\title{
AS MANGUEIRAS DE GILBERTO FREYRE: QUESTÕES DE LEGENDA CINEMATOGRÁFICA
}

\author{
Cristina DUARTE \\ Université de Toulouse - le Mirail
}

\begin{abstract}
A tradução no cinema suscita problemas bastante específicos. Deve-se lidar com uma imagem sempre em movimento, o que exige rapidez e concisão. A impossibilidade de recorrer a notas de rodapé para esclarecer uma palavra, expressão ou situação peculiar, acrescenta uma dificuldade suplementar, pois o espectador confronta-se em permanência com a presença do "Estrangeiro". 1

Por outro lado, é imprescindível lembrar que no cinema, na maior parte do tempo, trata-se de traduzir a fala, o que exige aptidões específicas que implicam não somente o conhecimento lingüístico de dois códigos, como também o conhecimento de regras pragmáticas: se o tradutor tentar criar na língua alvo o estilo ou gênero discursivo sugerido na língua fonte, mesmo que para isso tenha
\end{abstract}

\footnotetext{
${ }^{1}$ Para Albert Bensoussan, (Confessions d'un Traître, Rennes, Presse Universitaire de Rennes, 1995,) o tradutor moderno tem que levar em consideração um princípio básico: o respeito do Estrangeiro. Ele não deve incorporar a cultura desse Outro, mas deixar o leitor da língua alvo perceber que o texto que está lendo é oriundo de um lugar completamente diferente do seu. A arte do tradutor consiste então em passar despercebido, sem contudo eliminar esse Outro. Por isso, a tendência, hoje em dia, é a utilização cada vez mais freqüente do decalque, do empréstimo ou da aclimatação das palavras e expressões. Segundo o autor, ninguém mais ousaria empregar, por exemplo, a expressão "chá do Paraguai" em vez de "chá-mate" (p. 118).
} 
que perder a equivalência lingüística, terá feito um bom trabalho. ${ }^{2}$

Mas tudo acontece tão rapidamente no cinema que, na maioria das vezes, o espectador não tem tempo para perceber as incongruências de certas traduções, que permanecem imperceptíveis. É preciso ver o filme várias vezes ou então dispor de uma grande agilidade para ser capaz de percorrer as duas línguas concomitantemente.

Do ponto de vista técnico, duas modalidades de tradução cinematográfica são possíveis: a legendação e a dublagem. A primeira, ou seja, as legendas, tem custo bem mais baixo, pois um só tradutor pode executar a totalidade do trabalho. A segunda, porém, exige vários dubladores, em função do número de personagens do filme. Seu custo é, assim, bem mais elevado, pois é necessário respeitar o sexo e a idade dos personagens, bem como reproduzir as diversas nuanças da pronúncia de cada um deles: uma pessoa que tem certo sotaque, outra que gagueja, outra que comete erros de gramática, etc... Há também, no ato de dublar, uma maior submissão à oralidade, à harmonia sonora das palavras. É assim que, por exemplo, Rio de Janeiro torna-se Rio de Janère na versão francesa do filme Central do Brasil (Walter Salles, 1998). Primazia sonora, então, para que haja uma maior fluência comunicativa, o que, aliás, a língua coloquial da França autoriza sem nenhuma hesitação: muita gente vai a Saint Paul e não a São Paulo.

Além desses aspectos, a dublagem apresenta várias outras dificuldades, como as sublinhadas por Edmond Cary $^{3}$ : ela deve se submeter de forma imperativa à imagem do filme; o personagem não pode fazer um gesto e dizer algo que contrarie esse gesto, nem abrir a boca e não emitir nenhum som. $\mathrm{O}$ respeito de

\footnotetext{
2 Paulo VIZIOLI, "A Tradução de Poesia em Língua Inglesa: Problemas e Sugestões", in Malcolm COULTHARD e Carmen Rosa CALDAS-COUTHARD (Org), Tradução: Teoria e Prática, Florianópolis, Ed. da UFSC, 1991, p. 138), pp. 86-87.

${ }^{3}$ Edmond CARY, Comment faut-il traduire?, Condé-sur-Noireau, Presses Universitaires de Lille, 1985, pp.65-71.
} 
certas sonoridades deve ser minucioso, incessante e draconiano: não é possível inverter as aberturas e fechamentos da boca, não é possível dizer "a" quando na tela diz-se "b", insiste Cary. ${ }^{4}$ Perante esses obstáculos o autor indaga se não seria melhor declarar, uma vez por todas, que dublar não é traduzir, mas adaptar livremente e que a fidelidade ao texto inicial só surgiria então por acaso. ${ }^{5} \mathrm{Com}$ efeito, as dificuldades de ordem espaciotemporal parecem dominar o texto a ser traduzido que fica submetido totalmente à sucessão inexorável das imagens.

As legendas apresentam outros tipos de problemas. Primeiramente, estabelecem uma grande desigualdade pois excluem de entrada todas as pessoas analfabetas ou semiletradas. Em segundo lugar, contêm elementos bastante desconfortáveis para o espectador.

O primeiro desses estorvos são letreiros brancos sobre fundo claro, o que dificulta e chega até mesmo a tornar a tradução ilegível. Um exemplo recente desse inconveniente encontra-se no filme Cinema, Aspirinas e Urubus (Marcelo Gomes, 2005), em que a legenda branca de certas cenas dissolve-se completamente na clara imagem ensolarada do sertão nordestino.

Ademais, se o espectador de cultura ocidental lê da esquerda para a direita, a imagem, quanto a ela, não desfila, obrigatoriamente, nesse mesmo sentido: pode haver um movimento de câmera (travelling ou panorâmica) no sentido exatamente contrário; ou então, um elemento da imagem (personagem ou carro, por exemplo), pode se deslocar da direita para a esquerda. Gérard-Louis Gautier lembra que a conjugação desses dois tipos de leitura simultaneamente atrapalha a percepção total da imagem e torna bastante inconfortável a situação do espectador, principalmente em planos curtos ou com muita informação escrita. ${ }^{6} \mathrm{O}$ público não tem tempo para apreender tudo, o que torna sua tarefa extremamente

\footnotetext{
${ }^{4}$ Op. cit. p. 67.

${ }^{5}$ Op. cit. p. 67.

${ }^{6}$ Gérard-Louis GAUTIER, "La traduction au cinéma: nécessité et trahison", La Revue du Cinéma, Image et Son, Paris, nº 363, juillet/août 1981, pp.103-104.
} 
complicada e cansativa. Sem contar que, do ponto de vista espaciotemporal, as exigências são grandes: as legendas devem se ajustar perfeitamente à imagem do momento, sem decalagem nem prolongamento na imagem seguinte.

Uma observação mais atenta da tradução cinematográfica permite constatar várias anomalias, quer na legendação, quer na dublagem. $\mathrm{O}$ enfoque deste texto é trazer à baila questões relacionadas a certas incongruências de legendação, sabendo entretanto que a dublagem pode também apresentar grandes imprecisões e até mesmo negligências. Por exemplo, na versão dublada do filme Central do Brasil (Walter Salles, 1998), apresentada pela televisão, o nome de um dos irmãos do menino Josué, Isaías, foi traduzido por Isaac, erro que, felizmente, não foi repetido na versão legendada da película.

Partindo das diversas exigências de ordem técnica acima ressaltadas, voltemos ao nosso propósito para analisar certos casos bastante curiosos de legendação. Por exemplo, o dos letreiros do documentário francês La Fournaise Brésilienne (Christian Brincourt et Philippe Vieillescazes), apresentado pelo canal TF1 em janeiro de 1984. Naquela época, o Nordeste brasileiro estava vivendo a pior seca do século XX. Numa paisagem devastada, a câmera filma alguns flagelados; uma voz em off pergunta para uma mãe de família nordestina 
que está carregando no colo um bebê raquítico: "Consegue alimentar ele?" A mãe, talvez surpreendida pelo sotaque francês da pessoa que pergunta, em vez de responder, olha para o lado e diz, ao que parece, para uma outra pessoa: "Não tô nem entendendo o que ele tá dizendo", enquanto a legenda, mentirosa, propõe a tradução seguinte: "Je n'ai rien à lui donner." Há claramente aqui uma certa manipulação por parte dos autores do filme, talvez para fazer coincidir a resposta da infeliz com o tom miserabilista que a reportagem deseja transmitir... $\mathrm{Na}$ verdade, essa cena ilustra muito bem uma certa preferência da imprensa francesa por salientar aspectos de crise da sociedade brasileira, destacando exageradamente os problemas da dívida, as dificuldades sociais e políticas. ${ }^{7}$

No presente caso, a tradução apóia esse tipo de ideologia.

Numa outra cena do mesmo documentário, a voz do intérprete francês, fora de campo, interroga dois homens que estão abrindo uma picada na caatinga. Trata-se de operários da Frente de Trabalho, organismo criado para dar emprego e proporcionar salário mínimo para os pais de família vítimas da seca. A pergunta é a seguinte: "Você acha que isso tudo (o que estão fazendo) serve para algo?" - Ora, a palavra "algo" não faz parte do vocabulário desses homens miseráveis, na maior parte do tempo analfabetos, e um deles, confundindo "algo" e "água", responde: "Prá água, serve". A legenda francesa remenda o erro de compreensão e propõe como tradução: C'est un travail pour la pluie à venir. O problema aqui gerado vem de uma utilização inadequada da língua, ou melhor, de uma falta de conhecimento do nível de língua por parte da pessoa que interroga os nordestinos; ela é francesa e ainda não domina o português do Brasil para poder levar em conta certas sutilezas.

\footnotetext{
${ }^{7}$ André de SEGUIN, "A Impossível Objetividade" in Solange PARVAUX, Jean REVELMOUROZ, Imagens Recíprocas do Brasil e da França, Actas do Colóquio organizado no quadro do projeto França-Brasil, IHEAL, Paris, 1991, p. 85.
} 
Manipulação no primeiro caso, ingenuidade linguística no segundo, os motivos podem ser variados, mas as distorções estão ali, castigando a obra cinematográfica.

Um outro aspecto que pode ser observado freqüentemente nas legendas é a submissão total à etimologia. Esse princípio, que pode ser de uma grande eficacidade $^{8}$, torna-se nocivo quando a conservação da similitude gráfica da palavra leva a cometer imprecisões ou contra-sensos.

No filme Xica da Silva (Carlos Diegues, 1976) o "Contratador" torna-se o Contractant, escolha que pode ser facilmente compreendida, pois seria muito difícil impor nas legendas a expressão fermier $d u$ Roi. Por outro lado, um mau exemplo da aplicação desse princípio encontra-se no filme Barbosa (Jorge Furtado e Ana Luíza Azevedo, 1988). Esse curta-metragem conta o triste destino do homem que foi o goleiro da Seleção Brasileira de Futebol no jogo infeliz em que o Brasil perdeu a Copa do Mundo para o Uruguai, em 1950. No início do filme, o prefeito (le maire) do Rio de Janeiro faz um discurso lembrando que foi ele que construiu o estádio do Maracanã, lugar desse jogo decisivo; ele também incita os jogadores brasileiros, num delírio ufanista, a serem campeões do mundo. "Prefeito" foi traduzido por préfet. Preferiu-se a semelhança etimológica, mesmo se para tanto foi necessário cometer um falso sentido... Desde quando os préfets constroem estádios de futebol na França?

\footnotetext{
${ }^{8} \mathrm{Na}$ tradução de romances, é o que preconisa Claire Cayron: preferir, sempre que possível a palavra que tem a mesma etimologia. A autora chega até a aconselhar a criação de neologismos, mesmo se esse processo comporta uma conotação negativa em francês, língua, segundo ela, muito rígida. (Sésame, pour la traduction, Saint-Amand-Montrond, Le Mascaret, 1987, p. 13).
} 
Seguindo esse mesmo princípio, o filme $O$ Diabo a Quatro (Alice de Andrade, 2005) está sendo apresentado atualmente nas salas francesas com o título de Le Diable à Quatre. Efetivamente, a sonoridade, bem como o ritmo (número de palavras e de sílabas) parecem perfeitos. Mas será que essa expressão, que não faz nenhum sentido em francês, transmite plenamente a idéia de "coisas incríveis", "balbúrdia"? ?

Às vezes, a distorção aparece sorrateiramente, por exemplo no documentário Baden Powell (Jean-Claude Guiter, 2000). Nele, o grande compositor brasileiro, em visita à sua cidade natal, falando do avô e de vários membros da família já falecidos, pede para todos esses finados que o protejam e diz então: A bênção! A legenda propõe um enorme contra-senso: Je vous bénis, inversão infeliz que muda completamente o sentido da cena. A tradução proposta - contrariamente aos costumes brasileiros e ao verdadeiro sentido do ato - faz com que seja o vivo que abençoe e zele pelos mortos... ${ }^{10}$

A legendação cinematográfica parece também manejar sem muita perícia a polissemia de certas palavras, chegando a resultados bastante ridículos. Dentre esses, a estranha transformação das mangueiras de Gilberto Freyre (les manguiers) em tuyaux, no curta-metragem de Joaquim Pedro de Andrade $(O$ Mestre de Apipucos, 1959). Tradução surpreendente pois o contexto do filme é bastante explícito: o autor de Casa Grande e Senzala está no jardim de sua casa, passeando no meio das árvores e falando delas: "Gosto de caminhar pelos sítios cheios de mangueiras e jaqueiras desta velha casa..." A frase foi traduzida por: J'aime à me promener dans ce lieu rempli de tuyaux et de jaquiers de cette vieille maison.

\footnotetext{
${ }^{9}$ Dicionário Houaiss da Língua Portuguesa, Rio de Janeiro, Objetiva, 2004, p. 1028.

10 "Tomar a bênção: beijar a mão de alguém (...) ou disso fazer menção para pedir a proteção da sua bênção e a proteção divina". (Houaiss, op. cit. p. 432).
} 
Aliás, esse documentário não está isolado; faz parte de um conjunto mais amplo, composto de vários outros curta-metragens restaurados de Joaquim Pedro de Andrade, todos projetados pela TV5 durante o ano de 2005, "Ano do Brasil na França". As negligências continuam no filme Aleijadinho, realizado pelo autor em 1978. Neste, "nora", torna-se belle-sœur, erro repetido duas vezes, em dois momentos diferentes do filme. A primeira frase diz: "Segundo a descrição de Joana, nora do artista..." e foi traduzida por: Selon la description de Joana, la belle-sœur de l'artiste...Quanto à segunda: "Teve o rosto desfigurado, o que the conferiu, no dizer da nora, expressão asquerosa e sinistra", foi traduzida por : Son visage se défigura; cela lui conféra, d'après sa belle-sœur, une expression affreuse et sinistre.

Esquisito, esse "Ano do Brasil na França", em que a negligência das legendas transformam ambos os filmes numa espécie de Samba do Crioulo Doido $^{l 1}$ : Gilberto Freyre mais parece Monsieur Hulot, evoluindo entre tubos de borracha ${ }^{12}$, enquanto na Vila Rica de Antônio Francisco Lisboa, noras se transformam em cunhadas...

Outra questão a ser tratada diz respeito à precisão rígida da língua francesa quando enfrenta a extrema maleabilidade do português do Brasil. Um exemplo interessante desse fenômeno são os letreiros do curta-metragem A Velha a fiar. (Humberto Mauro, 1964) que faz parte das Brasilianas, canções tradicionais brasileiras. O princípio de A Velha a fiar é o da corrente: um primeiro elemento aparece na canção, a velha que está fiando; em seguida chega a mosca, depois a aranha, o rato, o gato, o cão, o pau, o fogo, a água, o boi, o homem, a

\footnotetext{
${ }^{11}$ Canção de autoria de Sérgio Porto e Stanishlaw Pontepreta que faz uma sátira dos sambas de enredo do Carnaval. O compositor/narrador perdeu o juízo e por isso mistura todos os elementos da História do Brasil, numa grande confusão.

${ }^{12}$ Personagem e situação burlescos do filme francês Mon Oncle de Jacques Tati (1956-58).
} 
mulher e por fim a morte. Doze elementos, no total. O texto brasileiro emprega um só verbo para todos esses elementos, a expressão "fazer mal":

Estava a velha no seu lugar

Veio a mosca lhe fazer mal

A velha na mosca, a velha a fiar

Estava a mosca no seu lugar

Veio a aranha lhe fazer mal

A aranha na mosca, a mosca na velha

A velha a fiar, etc.

Ora, essa expressão "fazer mal" é traduzida nos letreiros em francês por doze verbos diferentes, um verbo para cada um dos doze elementos: la mouche embête la vieille, l'araignée pique la mouche, la souris agace l'araignée, le chat attrape la souris, le chien attaque le chat, le bâton frappe le chien, le feu saisit le bâton, l'eau éteint le feu, le bæuf se baigne dans l'eau, l'homme monte le bouf, la femme ennuie l'homme, la mort emporte l'homme.

Observa-se, nesse caso, o nível de adaptação necessário para poder passar de uma língua para a outra; o português do Brasil deixa supor os diversos sentidos de "fazer mal", enquanto o francês exige uma definição exata das diversas ações. O que é ganho em precisão linguística é perdido em imaginação...

Por outro lado, com os problemas de espaço e de tempo que se colocam, traduzir no cinema é, como já vimos, sobretudo resumir; é necessário ser sintético e deixar tempo disponível para que o espectador possa ver o filme e não seja obrigado a passar o tempo inteiro lendo os letreiros. Um exemplo feliz do funcionamento desse princípio de síntese encontra-se no filme Meia-Noite (Walter Salles e Daniela Thomas, 1999) apresentado por Arte, na série 2000 Vu par..., no momento da mudança de milênio. Na humilde casinha da favela surge o 
personagem do malandro que, face à surpresa da mulher, diz: "Quem é vivo sempre aparece...", traduzido na legenda pelo bem mais conciso: Eh oui, un revenant!, que utiliza seis sílabas ao invés das nove da frase original, além de respeitar o nível do discurso.

Felizmente então, nem sempre as legendas apresentam anomalias. No documentário suíço sobre Maria Bethânia exibido atualmente na França (Música é perfume, Georges Gachot, 2005), não parece haver nenhuma imprecisão, os letreiros parecem transmitir exatamente o sentido das palavras e o espírito da obra. Resultado do primor helvécio?

Concluindo, os descuidos de tradução constituem um fenômeno que pode se manifestar tanto no curta-metragem de um diretor iniciante ou na rápida reportagem televisiva, como no grande filme do diretor premiado nos festivais internacionais. Será que os cineastas não têm nenhuma possiblidade de revisão dessas traduções? Ou melhor, será que não manifestam nenhum interesse em acompanhar essa fase derradeira das obras? Qual deve ter sido, por exemplo, a reação de Walter Salles quando Isaías tornou-se Isaac? E Joaquim Pedro de Andrade - diretor do inesquecível Macunaíma - será que não se sentiu agredido por todos esses tubos de borracha e por todas essas cunhadas que invadiram seus documentários sem terem sido convidados? Em suma, qual é a reação dos autores dos filmes diante de tanto atrevimento? 
